
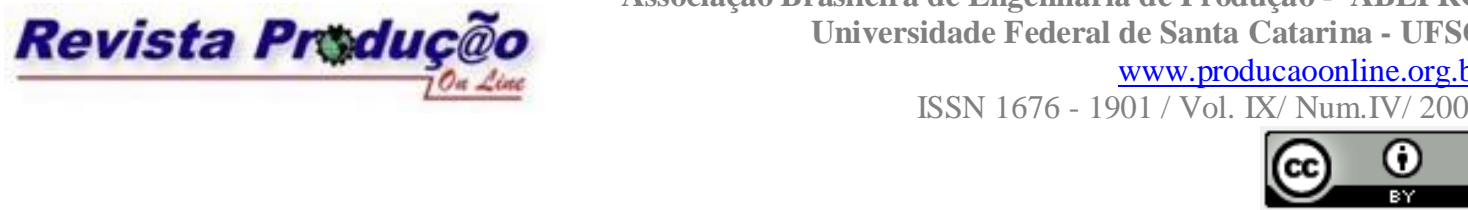

\title{
Ações estratégicas sistêmicas visando à integração da cadeia produtiva e de reciclagem de plásticos
}

\section{Systemic strategic actions for the integration of the productive chain and plastic recycling}

\author{
Liane Mählmann Kipper \\ Doutora em Engenharia de Produção \\ Departamento de Química e Física \\ Universidade de Santa Cruz do Sul -UNISC - Rio Grande do Sul - Brasil \\ e-mail: liane@unisc.br \\ Cláudia Mendes Mählmann \\ Doutoranda do Programa de Pós-Graduação em Engenharia de Minas \\ Departamento de Química e Física \\ Universidade de Santa Cruz do Sul -UNISC/ Rio Grande do Sul - Brasil \\ e-mail:mclaudia@unisc.br \\ Adriane Lawisch Rodríguez \\ Doutora em Engenharia/TU-Berlin \\ Departamento de Química e Física \\ Universidade de Santa Cruz do Sul - UNISC/ Rio Grande do Sul - Brasil \\ e-mail: adriane@unisc.br
}

\section{RESUMO}

Vivemos na sociedade do consumo, onde os impactos da industrialização e do crescimento populacional, bem como seus efeitos sócio-ambientais, nas áreas urbanas, estão entre os maiores desafios da atualidade. Nessa realidade a grande geração de lixo vem agravar o quadro ambiental. A reciclagem do resíduo plástico pode contribuir com a viabilidade econômica da reciclagem do lixo em geral, pois economiza matéria-prima, vem aparecendo com grande intensidade na massa de resíduos dos municípios brasileiros e apresenta grande conteúdo energético. Este trabalho apresenta estudo sobre a cadeia produtiva ou cadeia de valor (Supply Chain) que engloba os principais agentes na produção dos plásticos bem como sua reintrodução na cadeia após seu uso. No ponto de vista sistêmico, entende-se como cadeia de valor o desenvolvimento de inter-relações que buscam agrupar segmentos produtivos apresentando formas diferenciadas de cooperação de modo a promover melhorias no ciclo de 


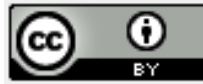

produção e consumo. A metodologia utilizada baseia-se na abordagem sistêmica e crítica, considerando que todas as variáveis envolvidas estão inter-relacionadas. De acordo com essa concepção pode-se definir a rede de reciclagem de plástico como uma unidade global organizada de inter-relações entre elementos, ações e indivíduos. Esses elementos não são unidades simples e sim relativas ao todo do qual fazem parte. Tendo como base essa concepção e o processo realizado pode-se propor que, para a existência de uma rede sustentável de reciclagem de plásticos em nível municipal e ou regional, exista um comitê gestor de resíduos sólidos visando à integração dos agentes e a auto-regulação necessária para a sustentação da rede de reciclagem de plásticos.

Palavras-chave: Resíduos; Plástico Pós-Consumo; Gerenciamento; Reciclagem

\begin{abstract}
We live in the society of the consume, where the impacts of industrialization and population growth, as well as its socio-environmental effects, in the urban areas, are among the highest challenges of present time. Such the huge waste generation, aggravates the environment panorama. Plastic residue recycling might contribute to economic viability of waste recycling in general, once it recovers raw material, present with great intensity in the mass residues of Brazilian cities, representing huge energy content. This work studies a supply chain that includes the stakeholders in the production of the plastics as well as reintroduction in the chain after use. In the systemic point of view, understood as supply chain the development of interrelations that look for to contain productive segments presenting differentiated forms of way cooperation to promote improvements in the production cycle and consume. The methodology is based on the systemic and critical approach, considering that all variables are interrelated. According to such conception the plastic recycling net can be defined as an organized global unit of Inter-relations among elements, actions and human beings. These elements are not simple units but relative to the whole which they are part of. Based in this conception and the process carried out, it is possible to propose: for a sustainable net of plastic recycling in municipal and or regional level, it is necessary a managing committee of solid residues is necessary with the goal of integrating the stakeholders and the necessary auto-regulation to maintain the net of plastic recycling.
\end{abstract}

Keywords: residues; plastic post-consume; management, recycling

\title{
1. Introdução
}

O presente artigo apresenta estudo sobre a cadeia produtiva ou cadeia de valor (Supply Chain) englobando os principais agentes na produção dos plásticos, bem como sua reintrodução na cadeia após seu uso. No ponto de vista sistêmico, entende-se como cadeia de valor o desenvolvimento de inter-relações que buscam agrupar segmentos produtivos apresentando formas diferenciadas de cooperação de modo a promover melhorias no ciclo de produção e consumo. São apresentados os principais agentes da cadeia, envolvendo a 
discussão da indústria petroquímica e geração dos inúmeros artefatos plásticos, definição da rede de reciclagem como uma unidade global organizada de inter-relações entre elementos, ações e indivíduos, e reconhecendo que esses elementos não são unidades simples e independentes e sim relativas ao todo do qual fazem parte. Diante das informações levantadas percebeu-se a necessidade de construção de ações estratégicas sistêmicas promovendo a existência de uma rede sustentável de reciclagem de plásticos em nível municipal e ou regional, com a criação de um comitê gestor de resíduos sólidos visando à integração dos agentes e a auto-regulação necessária para a sustentação da rede de reciclagem de plásticos.

\section{Conceitos}

Segundo Jobim Filho (2002) o conceito de cadeia de suprimento sustentável tem evoluído a partir dos conceitos de logística, cadeia de suprimentos e sustentabilidade. Existem vários conceitos sobre cadeia de valor, cadeia produtiva, cadeia de suprimentos, gerenciamento da cadeia e logística analisado sob diferentes prismas e percepções. Diversos autores definem cadeia produtiva intrinsecamente relacionada com a logística, como um conjunto de atividades econômicas necessárias as etapas de processamento transformando matérias-primas em produtos visando à satisfação dos clientes. Lopes (2000), acrescenta ainda que a cadeia de valor é formada por todas as atividades ligadas à empresa detectadas a partir das necessidades dos clientes consumidores até o estabelecimento das competências essenciais (relacionamento com fornecedores de matéria-prima, fabricação e distribuição dos produtos). Sob este ponto de vista percebe-se a necessidade de uma visão ampliada e com maior integração na cadeia de valor buscando sustentabilidade em todo o ciclo de vida do produto. Para que isto ocorra, a análise do uso e da destinação dos resíduos gerados por parte dos agentes do sistema deve ser considerada. Lerípio (2001) citado por Kipper (2005) afirma que aqueles resíduos que não puderem ser reutilizados ou reciclados não deveriam existir, isto é, o produto original deveria ser reprojetado, de forma que se evite a incineração e a destinação em aterros. Segundo Santos (2004) no gerenciamento do resíduo sólido urbano a reciclagem surge como uma das vias para reduzir os resíduos aterrados. No Brasil, os plásticos constituem uma das classes de materiais com menor índice de reciclagem, mesmo apresentado características interessantes para sua reintrodução nas cadeias produtivas. $\mathrm{O}$ mesmo autor considera que para aumentar os índices de reciclagem de modo sustentável há necessidade de investimentos em tecnologias inovadoras e economicamente viáveis. Neste 
aspecto um sistema de coleta adequado é um ponto chave para fazer o retorno do material a um novo processo de produção por meio da sua reciclagem ou reutilização desenvolvendo uma cadeia de suprimento reversa. Para que isto ocorra a existência de uma rede sustentável de reciclagem de plásticos em nível municipal e ou regional, envolvendo atores que participam desta atividades é fator primário para a sua organização. Um comitê gestor de resíduos sólidos formado pelo poder público, universidade, sociedade, associação de catadores, recicladores e transformadores, visando à integração dos agentes e a auto-regulação necessária para a sustentação da rede de reciclagem de plásticos pode ser desenvolvido considerando que sustentabilidade para todo o ciclo de vida e diminuindo a visão fragmentada da cadeia de valor.

\section{A Indústria Petroquímica e o Plástico}

Considerando os conceitos apresentados, os complexos industriais, como é o caso da indústria petroquímica, constituem cadeias produtivas que apresentam grande sinergia nos processos desenvolvidos. A indústria petroquímica é um setor distinto dos demais por utilizar frações derivadas do refino do petróleo ou do gás natural. O petróleo é um recurso mineral não-renovável em curto prazo, formado por uma gama de compostos. Por causa de sua variada composição, quando refinado, extraem-se diversos produtos, como gasolina, diesel, querosene, gás de cozinha, óleo combustível e lubrificante, parafina e compostos químicos. A estrutura de refino difere em função das exigências internas de consumo de cada país (PETROBRAS, 2005). No Brasil, o refino do petróleo produz os derivados representados na Figura 1. 

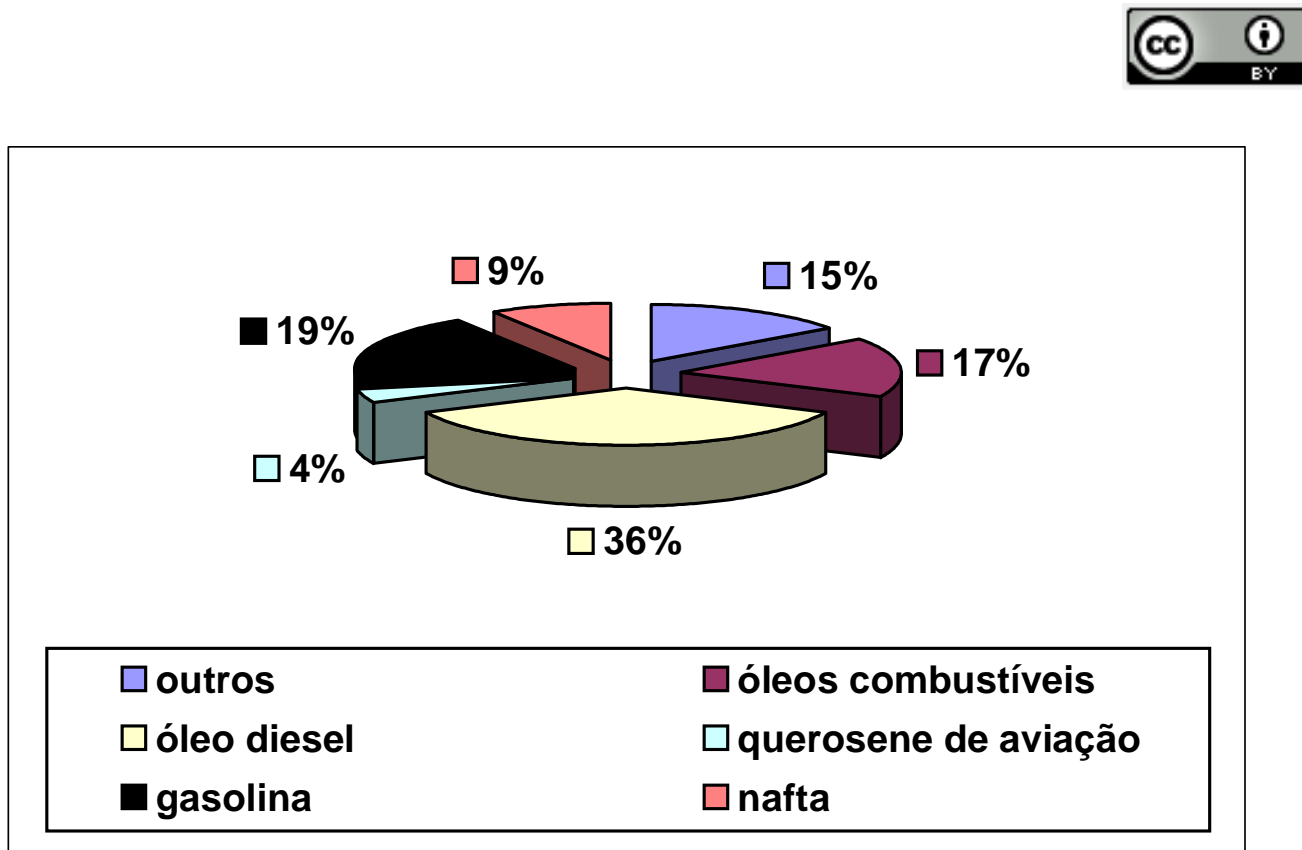

Figura 1 - Produção de derivados do petróleo no Brasil

Fonte: PETROBRAS (2005)

A matéria-prima básica para toda a cadeia de produção das resinas plásticas é a nafta. A PETROBRAS é a fornecedora exclusiva de nafta no Brasil, atendendo à demanda com a produção de suas refinarias e com importações. Segundo a Agência Nacional do Petróleo (2003), o Brasil produziu, de janeiro a setembro de 2002, 42,5 milhões de barris do produto e importou outros 12,6 milhões de barris. Após a extração e o refino do petróleo, a nafta é fornecida para três centrais de matérias-primas da indústria petroquímica brasileira: a Petroquímica União, em São Paulo, a COPESUL, instalada no Estado do Rio Grande do Sul, e a Braskem (antiga COPENE), na Bahia. Por meio de pesquisa bibliográfica e documental, foi possível resgatar que a petroquímica brasileira iniciou em 1955, com a implantação da refinaria de petróleo de Cubatão, onde surgiram inicialmente unidades produtivas de eteno, propeno, negro de fumo, metanol, amônia e fertilizantes nitrogenados. Nessa época, a indústria química brasileira não obedecia a um planejamento preestabelecido e os investimentos aconteciam de forma aleatória. No período de estudo, os três pólos petroquímicos estabelecidos no Brasil possuem planos de expansão e aumento da produção. $\mathrm{O}$ perfil idealizado para esse setor $\left(1^{\mathrm{a}}, 2^{\mathrm{a}}\right.$ e $3^{\mathrm{a}}$ geração) tem base em uma empresa que possui escala, acesso a matérias-primas, a preços e a qualidades competitivas, à distribuição de produtos a baixo custo e com rapidez, à tecnologia utilizada e a processos produtivos que não 


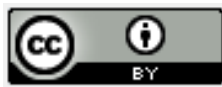

agridem o meio ambiente. No Quadro 1 são apresentados alguns dados dos pólos petroquímicos brasileiros. Por meio desses dados observa-se que existe forte relação entre a indústria de $1^{\mathrm{a}}$ e de $2^{\mathrm{a}}$ gerações do ramo petroquímico.

\begin{tabular}{|c|c|c|c|c|c|}
\hline Pólo & $1^{a}$ Geração & $\begin{array}{l}\text { Capacidade } \\
\text { Produtiva }\end{array}$ & $2^{\mathrm{a}}$ Geração & $\begin{array}{l}\text { Estratégia } \\
\text { Principal }\end{array}$ & Vantagens \\
\hline $\begin{array}{l}\text { São } \\
\text { Paulo }\end{array}$ & $\begin{array}{l}\text { Petroquímic } \\
\text { a União } \\
(1972)\end{array}$ & $\begin{array}{l}500 \text { mil ton./ano } \\
\text { de eteno na base } \\
\text { nafta }\end{array}$ & 39 empresas & Localização & $\begin{array}{l}\text { Mesmo sendo a } \\
\text { menor central } \\
\text { petroquímica, } \\
\text { tem vantagem } \\
\text { de logística, pois } \\
\text { se situa na } \\
\text { região mais } \\
\text { consumidora do } \\
\text { país. }\end{array}$ \\
\hline Bahia & $\begin{array}{l}\text { COPENE } \\
(1978)\end{array}$ & $\begin{array}{l}1,2 \text { milhões } \\
\text { ton./ano de eteno } \\
\text { na base nafta }\end{array}$ & 42 empresas & $\begin{array}{l}\text { Diversificação } \\
\text { de produtos }\end{array}$ & $\begin{array}{lr}\text { Produz } & \text { amplo } \\
\text { espectro } & \text { de } \\
\text { produtos } & \\
\text { químicos } & \text { (desde } \\
\text { petroquímicos } \\
\text { básicos r até } \\
\text { produtos } \\
\text { especiais) }\end{array}$ \\
\hline $\begin{array}{l}\text { Rio } \\
\text { Grande } \\
\text { do Sul }\end{array}$ & $\begin{array}{l}\text { COPESUL } \\
(1982)\end{array}$ & $\begin{array}{l}1,135 \text { milhões } \\
\text { ton./ano de eteno. } \\
\text { Principal base é a } \\
\text { nafta, mas pode } \\
\text { operar com } 45 \% \\
\text { da sua capacidade } \\
\text { com outras bases. }\end{array}$ & 08 empresas & $\begin{array}{|lr|}\text { Atualização } & \\
\text { tecnológica } & \mathrm{e} \\
\text { busca } & \mathrm{de} \\
\text { inovação } & \\
\end{array}$ & $\begin{array}{l}\text { Não depende só } \\
\text { da nafta e opera } \\
\text { em escala de } \\
\text { produção }\end{array}$ \\
\hline
\end{tabular}

Quadro 1 - Dados gerais sobre os pólos petroquímicos existentes no Brasil

Fonte: Adaptado de Freire e Jardim (2002)

Com relação às centrais de matéria-prima que são mais reconhecidas, como a indústria de primeira geração, elas realizam a destilação e o craqueamento da nafta, produzindo para a segunda geração das indústrias do setor mais de seis milhões de toneladas de petroquímicos básicos ou monômeros: eteno, propeno, xilenos, butadieno, benzeno e tolueno, e outros.

O Quadro 2 apresenta a capacidade instalada, em milhares de toneladas anuais, para os produtos derivados da nafta, descritos na frase anterior, dos pólos petroquímicos existentes no Brasil. 


\begin{tabular}{|l|l|l|l|l|}
\hline Produto & $\begin{array}{l}\text { PetroquímicaUnião- } \\
\text { SP }\end{array}$ & COPENE -BA & COPESUL - RS & Total \\
\hline Eteno & 500 & 1.200 & 1.135 & 2.835 \\
\hline Propeno & 250 & 570 & 581 & 1.401 \\
\hline Butadieno & 80 & 195 & 105 & 380 \\
\hline Tolueno & 75 & 65 & 91 & 231 \\
\hline Xilenos & 50 & 306 & 66 & 422 \\
\hline Benzeno & 200 & 455 & 265 & 920 \\
\hline Total & 1.155 & 2.791 & 2.243 & 6.189 \\
\hline
\end{tabular}

Quadro 2 - Produtos químicos e capacidade instalada de produção

Fonte: Associação Brasileira da Indústria Química (2003)

Em geral, a operação de um pólo petroquímico envolve quatro grandes cadeias produtivas:

- resinas termoplásticas: produzidas a partir de termoquímicos primários pelas indústrias de segunda geração e vendidas às indústrias de transformação plástica;

- elastômeros: também produzidos por empresas de segunda geração da petroquímica, para serem utilizados pelas indústrias de transformação de borracha;

- solventes: uma cadeia que abriga a indústria de tintas, calçados móveis, agroindústria e outros setores;

- combustíveis: cadeia formada pelos distribuidores de combustíveis.

A partir dos monômeros, por exemplo, os etenos e os propenos, fabricam-se nas indústrias de segunda geração os polímeros sintéticos conhecidos como resinas plásticas ou produtos intermediários. Os polímeros sintéticos mais encontrados no pós-consumo são os seguintes: polietileno (PE), polipropileno (PP), poliestireno (PS), policloreto de vinila (PVC) e o polietileno tereftalato (PET).

Nas indústrias de terceira geração, também conhecidas como indústrias de transformação, são gerados produtos plásticos a partir dos polímeros sintéticos. Com o objetivo de visualizar a forma como os plásticos estão inseridos na cadeia de produção da indústria petroquímica, e considerando que essa cadeia não finaliza na terceira geração, é apresentado o Quadro 3 com as principais entradas e saídas desse sistema.

Percebe-se, a partir da síntese descrita nesse quadro, que existe uma ruptura no que tange a vários aspectos desde a gestão, o planejamento e os incentivos existentes a partir da quarta geração. 


\begin{tabular}{|c|c|c|c|}
\hline Principais Agentes & $\begin{array}{l}\text { Principais } \\
\text { Entradas }\end{array}$ & Tipo de Organização & Principais Saídas \\
\hline $\begin{array}{l}\text { PETROBRAS e } \\
\text { importações }\end{array}$ & Petróleo & Refinaria & $\begin{array}{l}\text { Petróleo fracionado } \\
\text { (nafta, gás natural e } \\
\text { gasóleo) }\end{array}$ \\
\hline $\begin{array}{l}\text { COPESUL } \\
\text { COPENE } \\
\text { PQU }\end{array}$ & $\begin{array}{l}\text { Algumas das } \\
\text { frações: nafta e/ou } \\
\text { gás natural }\end{array}$ & $\begin{array}{c}\text { Primeira geração } \\
\text { petroquímica }\end{array}$ & $\begin{array}{l}\text { Petroquímicos básicos } \\
\text { (monômeros: eteno, } \\
\text { propeno, butadieno, } \\
\text { benzeno, ...) }\end{array}$ \\
\hline $\begin{array}{l}\text { Dezenas de } \\
\text { empresas }\end{array}$ & $\begin{array}{l}\text { Petroquímicos } \\
\text { básicos } \\
\text { (monômeros) }\end{array}$ & $\begin{array}{l}\text { Segunda geração } \\
\text { petroquímica }\end{array}$ & $\begin{array}{l}\text { Petroquímicos } \\
\text { intermediários } \\
\text { (resinas plásticas: } \\
\text { polietilenos, } \\
\text { plipropilenos, } \\
\text { poliestirenos,...) }\end{array}$ \\
\hline $\begin{array}{l}\text { Milhares de } \\
\text { empresas }\end{array}$ & $\begin{array}{l}\text { Petroquímicos } \\
\text { intermediários } \\
\text { (resinas plásticas) }\end{array}$ & $\begin{array}{l}\text { Terceira geração } \\
\text { petroquímica }\end{array}$ & $\begin{array}{l}\text { Plásticos: vários } \\
\text { produtos }\end{array}$ \\
\hline $\begin{array}{l}\text { Sociedade Brasileira } \\
\text { (milhões de } \\
\text { habitantes) }\end{array}$ & Produtos (plásticos) & $\begin{array}{c}\text { Quarta geração } \\
\text { Consumo-Descarte } \\
\text { Sociedade }\end{array}$ & Resíduos plásticos \\
\hline $\begin{array}{l}\text { Sociedade } \\
\text { Poder Público } \\
\text { Associações } \\
\text { Empresas }\end{array}$ & Resíduos plásticos & $\begin{array}{c}\text { Quinta Geração } \\
\text { Associações } \\
\text { Empresas Recicladoras }\end{array}$ & $\begin{array}{l}\text { Matéria-prima para a } \\
\text { terceira e/ou para a } \\
\text { segunda geração } \\
\text { petroquímica e/ou } \\
\text { geração de energia. } \\
\text { (retorno ao ciclo) }\end{array}$ \\
\hline
\end{tabular}

Quadro 3 - Principais agentes, entradas e saídas da cadeia produtiva da indústria petroquímica

Em relação ao plástico, é importante constar que ele é um polímero (que significa "muitas partes"). Polímero é uma molécula de alto peso molecular obtida pelo encadeamento sucessivo de pequenas unidades repetitivas de baixo peso molecular definidas como monômeros. Podem ser usados para aplicações de engenharia, como engrenagens e peças estruturais, que permitem o uso em substituição a materiais clássicos, particularmente metais. Nesse contexto, incluem-se os termoplásticos, que são plásticos que podem ser reversivelmente aquecidos e resfriados, passando respectivamente de massas fundidas a sólidos, podendo ser transformados, processados e reprocessados, por métodos tradicionais de transformação. Em síntese, pode-se dizer que esse sucesso depende de várias características que os plásticos possuem, onde destacam-se:

- peso reduzido;

- facilidade de fabricação e processamento;

- eliminação de tratamento anticorrosivo;

- alta resistência a impacto; 


\section{Revista Produç@o}

Associação Brasileira de Engenharia de Produção - ABEPRO

Universidade Federal de Santa Catarina - UFSC

www.producaoonline.org.br

ISSN 1676 - 1901 / Vol. IX/ Num.IV/ 2009

- bom isolamento elétrico;

- menor custo energético de fabricação e transformação;

- custo de acabamento reduzido;

- resistência à oxidação e a intempéries.

No Quadro 4 são apresentadas as relações conhecidas dos plásticos utilizados na fabricação de alguns produtos. Pode-se constatar uma gama de combinações possíveis para o fabrico de produtos com plásticos, isto é, frascos podem ser feitos com a maioria dos plásticos apresentados. Se não houver uma identificação correta e adequada sobre o tipo de plástico utilizado no fabrico do produto haverá problemas e até mesmo inviabilização do processo de reciclagem visando a geração de uma cadeia de suprimentos reversa.

\begin{tabular}{|l|l|}
\hline \multicolumn{1}{|c|}{ Produto } & \multicolumn{1}{c|}{ Tipo de Plástico } \\
\hline Baldes, garrafas de álcool, bombonas & PEAD \\
\hline Condutores para fios e cabos elétricos & PVC, PEBD, PEAD, PP \\
\hline Copos de água mineral & PP e PS \\
\hline Embalagens de massas e biscoitos & PP, PEBD \\
\hline Frascos de detergente e produtos de limpeza & PP, PEAD,PEBD e PVC \\
\hline Frascos de xampu e artigos de higiene & PEBD, PEAD, PP \\
\hline Garrafas de óleo & PET (rótulo PEBD e tampa PP) \\
\hline Garrafas de refrigerante & $\begin{array}{l}\text { PET (rótulo PEBD, tampa PP e } \\
\text { retentor EVA) }\end{array}$ \\
\hline Potes de margarina & PP \\
\hline Sacos de adubo & PEBD \\
\hline Sacos de leite & PEBD \\
\hline Sacos de lixo & PEBD, PEAD, PVC \\
\hline Sacos de ráfia (estopa) & PP \\
\hline
\end{tabular}

Quadro 4 - Tipos de Plásticos Utilizados na Fabricação de Alguns Produtos

Ressalta-se que pode ser observado nos exemplos descritos na tabela acima a possibilidade de produção de embalagens, utilizando-se plásticos distintos. Essa ação é um dos complicadores para os triadores e recicladores quando há necessidade de reutilização e de reciclagem dos mesmos. No exemplo dos frascos de detergente e de produtos de limpeza, é visível essa possibilidade, em que o fabricante de embalagens pode optar por tipos de plásticos variados no fabrico geralmente observando apenas o custo da matéria-prima e da adaptação das máquinas. Outro exemplo podem ser as garrafas de refrigerantes, em que em uma única embalagem encontram-se quatro tipos diferentes de plásticos. 


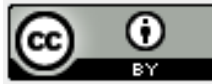

No Quadro 5 são apresentados os plásticos mais presentes hoje na massa de resíduos e os seus vários usos.

\begin{tabular}{|c|c|}
\hline Siglas & Usos \\
\hline PET & $\begin{array}{l}\text { Fibras têxteis; frascos de refrigerantes e de água mineral, cosméticos, } \\
\text { remédios, xampus, vinagres, detergentes, óleos comestíveis e outros; } \\
\text { mantas de impermeabilização; carcaças de bombas; componentes } \\
\text { para eletrodomésticos; e outros. }\end{array}$ \\
\hline PEAD & $\begin{array}{l}\text { Tampas; baldes, pás de lixo e outros utensílios domésticos; } \\
\text { vasilhames de alimentos; frascos em geral; componentes de } \\
\text { eletrodomésticos; garrafas de leite e iogurtes; brinquedos; sacos de } \\
\text { lixo e de supermercado; tubulações de água e gás; cabos coaxiais e } \\
\text { de comunicação; e outros. }\end{array}$ \\
\hline PVC ou V & $\begin{array}{l}\text { Tubulações de água e esgoto; tubos flexíveis; cortinas; divisórias; } \\
\text { carpetes; persianas; frascos para adoçantes; filmes transparentes para } \\
\text { embalar alimentos; revestimentos de cabos elétricos; lonas; calçados; } \\
\text { esquadrias; papel de parede; couro sintético; piscinas montáveis; } \\
\text { capas de chuva e outros. }\end{array}$ \\
\hline PEBD & $\begin{array}{l}\text { Sacos de supermercado e de lixo; frascos flexíveis; utensílios } \\
\text { domésticos; adesivos; cabos e fios; filmes para estufas agrícolas; } \\
\text { plastificação de papéis; e outros. }\end{array}$ \\
\hline PP & $\begin{array}{l}\text { Frascos; vasilhames para água mineral, refrigerantes, sucos e outros; } \\
\text { potes de produtos alimentícios; componentes de eletrodomésticos; } \\
\text { fibras têxteis, carpetes; filmes para embalagens; produtos moldados } \\
\text { para peças automotivas; dutos de ventilação; tampas de garrafa de } \\
\text { refrigerantes; utensílios médicos; copos; brinquedos; equipamentos } \\
\text { desportivos; seringas descartáveis; e outros. }\end{array}$ \\
\hline PS & $\begin{array}{l}\text { Copos descartáveis para água e café; utensílios domésticos rígidos; } \\
\text { indústria de eletrodomésticos; aparelhos de som e TV; e outros. }\end{array}$ \\
\hline Outros & $\begin{array}{l}\text { Há uma infinidade de outros plásticos. Dentre eles destacam-se: } \\
-\quad \text { Policarbonato (PC): CD's e DVD's; mamadeiras; capacetes e } \\
\text { escudos de segurança e ouros. } \\
-\quad \text { Acrilonitrila-Butadieno-Estireno (ABS): resina termoplástica } \\
\text { utilizada em freios de automóveis, eletrodomésticos, aparelhos } \\
\text { telefônicos e outros. }\end{array}$ \\
\hline
\end{tabular}

Quadro 5 - Uso dos plásticos mais presentes nos dias atuais na massa de resíduos

Fonte: Adaptado de Saldanha e Ludwig, 2001

Considerando o apresentado no quadro anterior, para a execução de uma cadeia de suprimentos reversa recomenda-se que exista no local de triagem (processo de separação) um quadro mural com exemplos de embalagens e sua respectiva identificação segundo a norma ABNT - NBR 13230 (1994). 


\section{O processo de Reciclagem}

Não há uma única definição para o ato de reciclar, mas este processo pode ser considerado como a ação de coletar, reprocessar, comercializar e utilizar materiais antes considerados como lixo. Assim, estes materiais são desviados, sendo colocados, separados e processados para serem usados como matéria-prima na manufatura de bens. Acrescenta-se também que a reciclagem não pode ser encarada como a única solução de todos os problemas dos resíduos sólidos, mas sim uma parte de um sistema de gerenciamento de resíduos. Assim, a reciclagem permite fazer o ciclo, trazendo de volta à origem, sob forma de matéria-prima, aqueles materiais que não se degradam facilmente e que podem ser reprocessados, mantendo suas características. Ela depende de outras atividades, gerando um sistema que se realimenta, um ciclo. A Figura 2 demonstra, de forma sintética, esse ciclo.

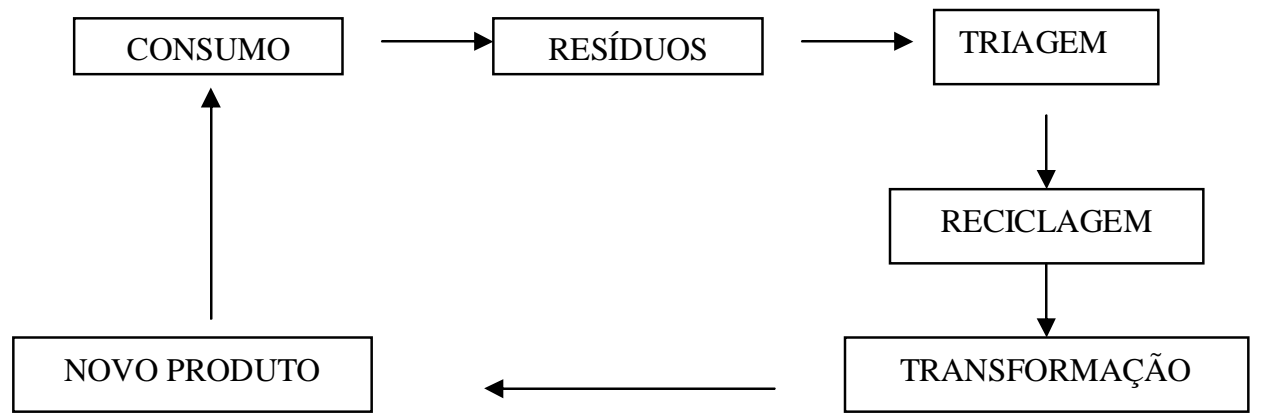

Figura 2 - Atividades relacionadas com a reciclagem

A reciclagem trata o plástico pós-consumo como matéria-prima, gerando a possibilidade de criação de novos produtos e trazendo benefícios para a população. Como benefícios que resultam da reciclagem de plásticos, podem ser citados os seguintes:

- diminuição da quantidade de resíduos enviados aos lixões;

- diminuição do consumo de energia;

- contribuição para a limpeza da cidade;

- conscientização dos cidadãos a respeito do destino dos resíduos e do valor que eles possuem;

- geração de empregos.

Mesmo assim, o índice de reciclagem de plástico em 2000 ficou em torno de $12 \%$ (Borges, 2000) em relação ao que é produzido, o que é considerado um valor ainda muito baixo. Estima-se que em 2010 o índice de reciclagem de plásticos passará a ser de 30\% 


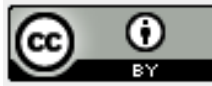

(Ferro, 2002). A reciclagem de resíduos, no Brasil, enfrenta muitos problemas, o que faz que ela não tenha deslanchado.

Em uma reportagem realizada pela revista Plástico Moderno (Sino Reto, 2001), foi apresentado o censo realizado por essa organização em 2000, identificando dois obstáculos para a expansão da atividade: a tributação sobre o material reciclado, que cultiva a informalidade, e a falta de sistemas de coleta seletiva, fonte de materiais limpos e descontaminados de resíduos orgânicos.

O IPI pago pelo plástico reciclado superava o do virgem, em agosto de 2000, quando o Governo Federal decidiu baixar a taxa de ambos para 5\%. Ainda assim a injustiça permanece, pois outros materiais recicláveis, como o vidro e o alumínio, são totalmente isentos. Além disso, o material reciclado paga novamente o ICMS já recolhido na comercialização do produto que o originou.

A área tributária do governo entende que quando uma resina pós-consumo segue para o processo de reciclagem, inicia-se outro ciclo industrial (Briones, citado por Sino Reto, 2001). Segundo Kapaz (2002), deveria existir no Brasil o conceito de "empresa exclusivamente recicladora" e para essa deveria haver a isenção de impostos, acabando com a bitributação, auxiliando tanto o catador que poderá obter mais lucro com a venda de materiais reciclados, como a indústria que pagará mais barato pela matéria-prima.

Assim, para ocorrer o desenvolvimento da reciclagem de plásticos, algumas questões básicas devem ser resolvidas, entre as quais as mais importantes estão apresentadas no Quadro 6 disposto a seguir.

Outro fator importante na comparação do uso de matéria-prima virgem e/ou reciclada vem dos estudos de análise de ciclo de vida. Esses estudos demonstram que quanto maior o índice de reciclagem maior é a redução dos resíduos sólidos, dos níveis de emissão para o ar e a água e do consumo de energia, água, petróleo e gás natural. (SPINACÉ E DE PAOLI, 2005) Segundo Arena, Mastellone e Perugini (2003) em 2001 foi realizado um estudo na Itália de análise de ciclo de vida de embalagens recicladas de PET e de PE.

Os resultados demonstraram que para a produção de $1 \mathrm{~kg}$ de flakes de PET reciclado são consumidos entre 42 e 55 MJ de energia, enquanto que para a produção do polímero virgem são necessários mais de 77 MJ. Para o polietileno (PE) reciclado são necessários de 40 a $49 \mathrm{MJ}$, enquanto que para a produção do polímero virgem são necessários em média, $80 \mathrm{MJ}$ de energia. 


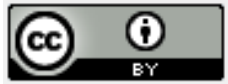

\begin{tabular}{|c|c|}
\hline Questão a ser resolvida & Explicação \\
\hline Incentivo fiscal & $\begin{array}{l}\text { O Imposto sobre Produtos Industrializados - IPI foi cobrado em } \\
\text { percentual superior no caso de plásticos reciclados ( } 12 \% \text { x } 10 \% \\
\text { para a embalagem confeccionada a partir de matéria-prima virgem). } \\
\text { No } 2^{\circ} \text { semestre de } 2000 \text {, foram equiparados os impostos } \\
\text { mencionados. A tendência foi a de que, em } 2001 \text {, houvesse uma } \\
\text { redução no imposto pago pelo reciclador (Sino Reto, 2000). Isso } \\
\text { não ocorreu. A partir de } 2002 \text { o plástico pós-consumo foi taxado em } \\
15 \% \text { de IPI para o PET e } 5 \% \text { para os demais. }\end{array}$ \\
\hline $\begin{array}{l}\text { Aquisição de matéria- } \\
\text { prima }\end{array}$ & $\begin{array}{l}\text { A falta de um gerenciamento integrado do lixo prejudica o } \\
\text { fornecimento de material a ser reciclado com uma freqüência } \\
\text { necessária para a produção não parar. }\end{array}$ \\
\hline $\begin{array}{l}\text { Qualidade da matéria- } \\
\text { prima }\end{array}$ & $\begin{array}{l}\text { Normalmente, os materiais fornecidos por catadores, sucateiros ou } \\
\text { atravessadores para as recicladoras não apresentam homogeneidade. } \\
\text { A perda relacionada à quantidade de material fornecido e a } \\
\text { quantidade de material que realmente vai ser reciclado chegaram a } \\
40 \% \text {, isso no caso dos recicladores que trabalham com material } \\
\text { oriundo de "lixão". }\end{array}$ \\
\hline Tecnologia & $\begin{array}{l}\text { A falta de tecnologia causa problemas, como por exemplo: gastos } \\
\text { excessivos de energia e de água e altos custos ligados à produção. } \\
\text { Muitas empresas fecham antes de completar } 2 \text { anos no mercado. }\end{array}$ \\
\hline $\begin{array}{l}\text { Qualidade do material } \\
\text { reciclado }\end{array}$ & $\begin{array}{l}\text { Alguns produtos entram no mercado sem qualidade, o que conduz a } \\
\text { desconfianças na aquisição. Isso, também, vem prejudicar a } \\
\text { imagem das empresas do ramo que trabalham seriamente. }\end{array}$ \\
\hline Mercado consolidado & Há poucos mercados diferenciados para materiais reciclados. \\
\hline
\end{tabular}

Quadro 6 - Relação de alguns pontos cruciais para o desenvolvimento da reciclagem de plásticos

Fonte: Adaptado de Pacheco e Hemais, 2000

Considerando também o fluxograma apresentado na Figura 3, o qual representa as etapas da cadeia de produção (da primeira até a terceira geração) e de reciclagem de plásticos, pode-se observar que existem vários caminhos que podem ser percorridos pelo plástico até sua reciclagem.

Acrescenta-se ainda que a partir da etapa de geração existe uma rede de agentes e interações em nível municipal, onde o plástico para ser reintroduzido no processo produtivo é tratado. 


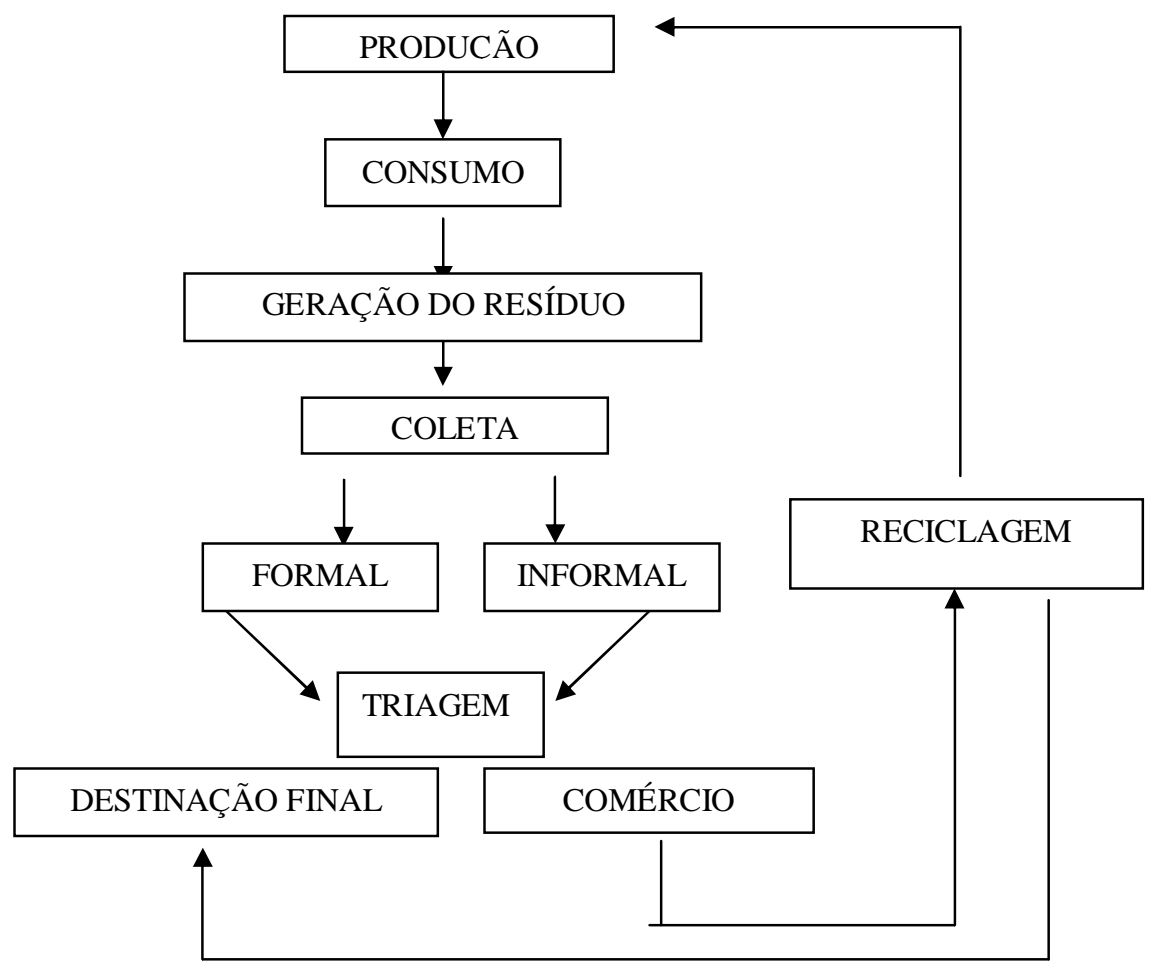

Figura 3 - Rede de produção e de reciclagem de plásticos

O modelo de fluxo apresentado na Figura 3 traduz as etapas da rede de reciclagem de plásticos, onde os principais agentes envolvidos atuam. Cada etapa pode ser considerada um subsistema. Destaca-se a importância dos atores em qualquer sistema e nos seus subsistemas, pois são eles os elos intra e entre os subsistemas que compõem o sistema e assim depende deles o êxito ou não de qualquer atividade empreendida. Nesse contexto, é importante descrever algumas características inerentes a esses agentes. Considerando a partir da geração do resíduo os principais agentes são: na coleta formal e triagem( lixeiros/unidades de triagem), na coleta informal e triagem(associações de catadores e catadores autônomos), na coleta, triagem e comercialização estão os intermediários ou sucateiros e na revalorização do resíduo(transformação do plástico pós-consumo) estão os recicladores ou indústrias de transformação. É percebido que a existência de associações de catadores e catadores autônomos apresenta relevância na ampliação do fluxo reverso de materiais ao processo de transformação.

Para os catadores de rua, ou simplesmente para o catador, pode-se dizer que as atividades a eles relacionadas geralmente são as seguintes: coleta os resíduos com valor 


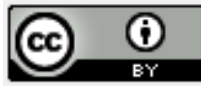

econômico (plástico, metal, papel, vidros e outros), transporta os materiais coletados para um local onde fará a separação dos mesmos, prensa e enfarda, havendo condições, para a comercialização ao sucateiro e/ou para o reciclador.

Em 2000, a profissão de catador foi reconhecida no Brasil mediante sua inclusão na CBO - Classificação Brasileira de Ocupações. Nesse documento há uma descrição sumária dessa atividade: catam, selecionam e vendem materiais recicláveis como papel, papelão e vidro, bem como materiais ferrosos e não-ferrosos e outros materiais reaproveitáveis. (Classificação Brasileira de Ocupações, 2008) Os catadores geralmente estão em um estado não-organizado, trabalham em micro escala, isto é, comercializam pequenas quantidades de materiais. Já os sucateiros, geralmente possuem melhores condições financeiras e locais de armazenagem, trabalhando com produção em macro escala. Geralmente se organizam em redes, que podem ser constituídas de pequenos sucateiros até de grandes cartéis. Quando isso ocorre são denominados intermediários ou atravessadores.

Quanto aos lixeiros ou às unidades de triagem, descritos na Figura 3, representam a coleta formal realizada pelo poder público municipal. Na maioria das cidades brasileiras essa coleta é terceirizada, em que a empresa responsável por coletar os resíduos pós-consumo utiliza instrumentos mecanizados, como, caminhões compactadores para coleta e transportes. Para a triagem, são empregadas as conhecidas usinas de triagem, providas de vários equipamentos, como por exemplo, funil dosador, esteira para separação, prensas, dentre outros.

Já os recicladores de plástico brasileiros, geralmente realizam, no início, um tipo de reciclagem denominada mecânica, transformando o resíduo plástico advindo do catador, e/ou da indústria de transformação e/ou do sucateiro em pellet (pedaços) e/ou em flake (flocos). Para agregar mais valor ao produto gerado, alguns recicladores realizam também o processo de transformação utilizando os pellets ou os flakes para gerar novos produtos que serão introduzidos novamente no mercado.

\section{Considerações finais}

Da análise da cadeia petroquímica percebe-se que há grande sinergia e dependência entre os elos da cadeia, ou seja, da primeira geração até a terceira geração as interações são sólidas e fortes formando uma cadeia de manufatura sustentável. Dos estudos realizados percebe-se também que há planos de expansão e ampliação da geração de produtos advindos 
dessa cadeia de suprimentos. A geração de resíduos esta intrinsecamente relacionada com o modo de consumo e por isto é considerado por muitos autores o grande vilão no aumento da geração de resíduos. Entretanto, considerando que sustentabilidade vai além dos limites da industrias, cabe também as indústrias da terceira geração petroquímica repensar na geração de produtos de uma forma sustentável buscando agregar informações ao cliente sobre as formas mais adequadas de descarte após seu uso para que o mesmo retorne ao ciclo de produção. Caso isto não possa ser realizado há necessidade de reprojetar estes produtos de forma que sejam considerados ecologicamente corretos.

Da análise de toda a cadeia de valor que engloba os principais agentes na produção dos plásticos bem como sua reintrodução na cadeia após seu uso percebe-se que entre a terceira geração e a quarta geração (consumo, descarte, sociedade) há uma ruptura entre estes elos existindo pouca ou nenhuma interação. Na quarta e quinta geração percebe-se vários pontos cruciais para o desenvolvimento da reciclagem de plásticos como foi apresentado no Quadro 3 presente neste artigo. Com relação ao processo de reciclagem de plásticos, percebese que, se não houver a contribuição de todos os atores a tendência é a da não-sustentação de todo o sistema. Se o foco estiver apenas nos ganhos financeiros, sem levar em conta aspectos ambientais e sociais, ele contribuirá para o esgotamento de toda a matéria-prima existente nesse sistema. Bons resultados a serem alcançados nesse setor também dependem de investimento em etapas anteriores e posteriores à reciclagem, ou seja, na coleta seletiva e no mercado para o produto reciclado.

A atuação conjunta de governo, universidades, organizações não-governamentais e recicladores, pode gerar incentivos para a reciclagem no país, levando a mais indústrias entrarem nessa atividade. O fortalecimento das cooperativas ou associações de catadores também pode auxiliar na logística do gerenciamento do lixo. Essas cooperativas são responsáveis por grande parte da separação de materiais que estão sendo reutilizados ou reciclados no Brasil. Para o resíduo plástico sua identificação e separação é fator crucial para sua posterior reintrodução na cadeia de valor. Se não houver uma gestão pública eficiente e comprometida com a inclusão social desses atores e não com o assistencialismo para os mesmos, a tendência é de que esses atores sejam explorados pelos sucateiros ou pelos intermediários, gerando não-interação e degradação de todo o sistema. 


\section{Referências}

ANP. Anuário Estatístico Brasileiro do Petróleo e do Gás Natural 2002. Agência Nacional do Petróleo. Rio de Janeiro, 2003.

ASSOCIAÇÃO BRASILEIRA DE NORMAS TÉCNICAS. NBR 13230: simbologia indicativa de reciclabilidade e de identificação de materiais plásticos. Rio de Janeiro, 1994.

ARENA U.; MASTEllONE, M. L.; PERUGINI, F. International Journal of Life Cycle Assessment, v.8,n.92. 2003.

ASSOCIAÇÃO BRASILEIRA DA INDÚSTRIA QUÍMICA. Anuário da indústria química 2002. Ano 29. São Paulo Abiquim, 2003. 281 p.

BORGES, C. Recicle a Natureza Agradece. Revista Pack, São Paulo, Ano 3, n.29, p. 12-13, jan., 2000.

CBO - Classificação Brasileira das ocupações. Disponível em: < http://www.mtecbo.gov.br/busca.asp>. Acesso em: 15 de março de 2008.

FERRO, S. Especialistas prevêem futuro e tendências do setor até 2010. Plástico Moderno, São Paulo, p.18-30, dez/jan. 2002.

FREIRE, J. R. D.; JARDIM, F. P. O futuro da indústria petroquímica gaúcha. Disponível em: 〈http://read.ufrgs.br/read16/artigo/artigo3.htm> . Acesso em: 16 de março 2002.

JOBIM FILHO, H.; JOBIM, M. S. S. \& ESTRADA, R. J. S. Proposta de integração das cadeias de suprimentos da indústria da construção civil através do gerenciamento sustentável. Anais do XXII Encontro Nacional de Engenharia de Produção, Curitiba - PR, 23 a 25 de outubro de 2002.

KAPAZ, E. Reciclagem Plástico Moderno, São Paulo, p.27-29, dez/jan. 2002.

KIPPER, L. M. Ações estratégicas sistêmicas para a rede sustentável de reciclagem de plásticos. 2005. 241 f. Dissertação (Doutorado em Engenharia de Produção) - Centro Tecnológico, Universidade Federal de Santa Catarina, Florianópolis.

LOPES, L. S. F. Como tornar uma empresa competitiva e globalizada. Makron Books, São Paulo, 2000.

PACHECO, E. B.; HEMAIS, C. A. O desenvolvimento da reciclagem de plásticos no Brasil. In: Congresso Brasileiro de Defesa do Meio Ambiente, Anais... Rio de Janeiro: UFRJ, 2000.

PETROBRAS. Produção de derivados no Brasil. Disponível em: < http://www2.petrobras.com.br >. Acesso em: 02 de fevereiro de 2005.

SALDANHA, J. e LUDWIG, R. M. O plástico nosso de cada dia. Porto Alegre: Livreto, 2001.

SANTOS, A. S. F.; AGNELli, J. A. M.; MANRICH, S. Tendências e desafios da reciclagem de embalagens plásticas. Polímeros: Ciência e Tecnologia. Vol. 14, n $\mathrm{n}^{\mathrm{O}}$ 5. p. 307 312, 2004.

SINO RETO, M. A. Tributação Espreme o Reciclador e Breca Expansão do Setor. Plástico Moderno, São Paulo, p.10-26 set. 2000.

SINO RETO, M. A. Transformação injeta US\$ 9,7 bilhões para dobrar de tamanho. Plástico Moderno, São Paulo, p. 10-16 dez/ jan. 2001. 


\section{Revista Produç@o}

Associação Brasileira de Engenharia de Produção - ABEPRO

Universidade Federal de Santa Catarina - UFSC www.producaoonline.org.br ISSN 1676 - 1901 / Vol. IX/ Num.IV/ 2009

SPINACÉ, M. A. da S.;DE PAOLI, M. A. A tecnologia da reciclagem de polímeros. QuímicaNova. V. 28, n. 1, p. 65 - 72, 2005.

Artigo recebido em 23/06/2009 e aceito para publicação em 15/12/2009. 